\title{
FRIENDSHIP FORMATION BETWEEN VISUALLY IMPAIRED AND NON-VISUALLY IMPAIRED PUPILS IN SELECTED INCLUSIVE BASIC SCHOOLS IN GHANA
}

\author{
Adam Awini ${ }^{i}$ \\ Department of Special Education, \\ University of Education, \\ Winneba, Ghana
}

\begin{abstract}
:
The purpose of the study was to describe the nature of friendships formations that exists between pupils with visual impairment and their non-visually impaired peers in 3 inclusive schools in Ghana. I adopted a phenomenology research design in recruiting 14 pupils with visual impairment in this study. One-on-one interviews were used to collect data for the study. Using thematic analysis, data from the one-on-one interviews were manually analyzed via themes that emerged from the data. Results from the study showed that there existed some levels of friendships between the non-visually impaired and non-non-visually impaired pupils in the schools and this friendship formations centred on assistance provided by the non-visually impaired. While some of the pupils noted that they mutually engaged in positive relationship with non-visually impaired, some thought otherwise and yet others described it as only perfunctory. I recommended that educational authorities in Ghana should put in place, a policy in schools that will solely focus on the formation of friendship between pupils who are visually impaired and the non-visually impaired. Teachers should help develop the capacity of both pupils with and without visual impairments to make and maintain stable and satisfying friendships through play and group activities.
\end{abstract}

Keywords: basic schools, friendship formation, visual impairments, inclusive education

\section{Introduction}

Friendship formation of pupils with special educational needs is a key issue in any educational agenda of a country and therefore, should be looked into appropriately (UNESCO, 2017). Friendship formation of pupils with visual impairments in regular schools cannot be overlooked since it facilitates their overall socialisation and participation in the mainstream of society. The nature of friendship that exist in schools may influence pupils' performances in all spheres of life. Maximizing positive friendship

${ }^{i}$ Correspondence: email awiniadam1975@gmail.com 
between pupils with and those without special needs may generally be considered an important aspect of placing them in regular schools (Lehohla \& Hlalele (2012:189-201; Estell, Jones, Pearl, \& van Acker, 2009: 110-124). Friendship formation in this study, have been conceptualized in a number of different ways that are only overlapping. These variables are categorised into positive relationships or friendships, social contact or interactions, peer acceptance, and the pupils' own social self-perceptions that may influence their acceptance by their classmates. "Friendship" or "relationship" focuses on companionship and membership in networks of students.

\section{Literature Review}

Disability is a major component of Sustainable Development Goal (SDGs) 4, 8, 10, 11, 17. Goal 4 for instance, calls for inclusive and equitable quality education and promote lifelong learning opportunities for all for all by 2030. It emphasizes inclusion and equity as laying foundations for quality education and learning. SDG 4 also calls for building and upgrading education facilities that are child-, disability-, and gender-sensitive and for providing safe, non-violent, inclusive and effective learning environments for all. To achieve this ambitious goal, countries should ensure inclusion and equity in and through education systems and programs. This includes taking steps to prevent and address all forms of exclusion and marginalization, disparity, vulnerability and inequality in educational access, participation, and completion as well as in learning processes and outcomes. It also requires understanding learners' diversities as opportunities in order to enhance and democratize learning for all students (UNESCO, 2017). Studying friendship formation between pupils with visual impairment and their non-visually impaired peers in Inclusive schools in Ghana will be rendering essential information to the nation as far as the success of the inclusive agenda is concerned. A number of studies have revealed that skills for developing and keeping friendships are often learned at school (Prince, 2010; Foley, Blackmore, Girdler, O’Donnell, Glauert, Llewellyn \& Leonard, 2012: 375391). Publishing this study will accelerate progress towards Ghana's achievement of the disability-related SDGs by the year 2030.

While inclusive education provides a favourable setting for achieving equal opportunities and full participation, their success requires a concerted effort, not only by teachers or school staff, but also by their non-disabled peers. It is within this context that those with disabilities can achieve educational progress and participation in inclusive settings Pupils with visual impairments' co-operation with peers and the development of close friendships are related to enduring happiness and well-being. Friendship as noted by Meyer and Bevan-Brown (2005) is the essence in human existence and as essential foundations for all pupils' social participation and learning. Friendship formation with peers fosters the formation of meaningful relationships, social competence and psychosocial well-being (King, Law, King, Rosenbaum, Kertoy \& Young, 2003: 63-90). Pupils with visual impairments have a sense of belonging and being believed in by others as key factors associated with success in life (King, Chaters, Miller, 
MacKinnon \& Havens, 2000: 734-739). Robinson and Truscott (2013) noted that making and maintaining friendships is a primary theme that emerges as critical to a sense of belonging in school for students with disabilities. For pupils with visual impairments, there are a range of friendship experiences, appearing as a strengthening bond, a protective feature, and also a tension and a strain.

Avramadis (2012) examined the friendships of primary school children with and without disabilities in England. Although, it was found out that these students were less popular than students without disabilities, they were equally likely to be members of the friendship clusters of the class and occupied similar levels of network centrality as their non-disabled peers. In contrast, a large-scale study from Norway, found out that students with disabilities and those with behaviour problems, had a considerably more difficult time finding and keeping friends (Frostad \& Pijl, 2007: 15-30). Lehohla and Hlalele (2012:189-201) asserted that friendships have major implications for positive emotional and academic development and protect against the negative impact of general peer rejection. The social skills defect evident in many children with visual disabilities may, however, lead typically achieving learners to avoid forming friendships with them or exclude them in certain educational and social activities (Estell et al., 2009). In inclusive settings, learners with special needs have an opportunity to have appropriate peer modelling and what it takes to be part of a team with people without disabilities. For pupils in basic schools, having a friend is one of the most important aspects of schooling. Friendships serve a wide array of purposes that include social and academic enhancement, and they improve lives in families and thus, the wider community (Lehohla \& Hlalele, 2012).

Gaps exist in the Ghanaian context as far as friendship formation in schools practising inclusive education is concerned. The 'vision' of the Ghanaian curriculum recognises the social nature of learning by stating that young people should be "confident, connected, actively involved, lifelong learners" (Ministry of Education, 2005:7). 'Confidence' and 'connectedness' emphasize being able to relate well with others, being effective user of communication tools, and being a member of local and international communities (friendship network). 'Actively involved' refers to pupils' participation in a range of life contexts. These relationships stand in both typical and mainstreamed schools where pupils with mild disabilities attend and can be largely attributed to the fact that social participation is one of the most significant predictors of pupils' future adjustment in society, as well as their affective and behavioural problems (Sandstrom, Cillessen \& Eisenhower, 2003: 530-550). Avoke and Avoke (2004) contended that only inclusion has the potential to reduce fear and build friendship, respect and understanding among pupils. All pupils, therefore, need an education that will help them to develop relationships and to prepare them for a life in the mainstream system. Pupils with visual impairment can have difficulties in building relationships with peers in regular school settings. They may appear to represent the assertion made by McCollum (1998:184); that "the fly caught in the spider web is included, but victimized". Studies have found out that within the group of pupils with disabilities, pupils diagnosed with sensory disorders find 
it particularly difficult to build relationships with typical peers and are at risk of becoming isolated in the classroom (Chamberlain, Kasari \& Rotheram-Fuller, 2007: 230242).

Ghana started the inclusive education project in the 2003/2004 academic year. Ghana National Basic School at Cape Coast, Avakpedome Basic School, and St. Joseph College of Education Basic School in Volta and Brong Ahafo Regions respectively were chosen by the Ghana Education Service to enrol pupils with visual impairments into the regular system. With policy development towards inclusion in Ghana, very little is known about the social dimensions of such initiatives for pupils with visual impairments and their mainstream peers. Sensory impairments affect functioning ability in all life domains and, as suggested by recent research evidence, vision impairments are related to social isolation and reduced quality of life (Nollett et al., 2019; Elsman, van Rens, \& van Nispen, 2019). Evidence about the social interactions and the quality of life of people with vision impairments is limited and infrequent (Chak \& Rahi, 2007). In existing evidence, adults are usually the main focus (because of the higher prevalence), and only a few studies focus on adolescents (Elsman, et al., 2019; Chadha \& Subramanian, 2011; Chak \& Rahi, 2007). The establishment of friendships between pupils with special needs and their typical peers is a major issue for inclusive education. However, very little is known about the social dimensions of such initiatives on the pupils with visual impairments in Ghana. Even though, inclusive education is to bring pupils with special needs and those without disabilities together, it appears the nature of the relationships that exists between them in regular schools have not been considered or researched into adequately to enhance the knowledge and practice of teachers and other practitioners. This study therefore sought to describe the nature of friendships formation that exists between pupils with visual impairment and their non-visually impaired peers in three (3) inclusive schools in Ghana.

\section{Method}

\subsection{Phenomenology Research Design}

A Phenomenology design was chosen to guide the qualitative aspect of the study. A phenomenological study describes the meaning of individuals lived experiences of a concept or a phenomenon. Phenomenologists focus on describing what all participants have in common as they experience a phenomenon (example, grief, friendship, which are universally experienced). Creswell (2007) noted that the basic purpose of phenomenology is to lessen an individual experiences of a phenomenon to a description of the universal essence, that is, a grasp of the very nature of the things. The phenomenologic approach sees the individual and his or her world as so interconnected that essentially the one has no existence without the other. To this end, qualitative researchers identify a phenomenon as an object of human experience. The inquirer then collects data from persons who have experienced the phenomenon and develops a composite description of the essence of the experience for all of the individuals. This 
description consists of what they experienced and how they experienced it (Moustakas, 1994) cited in Creswell (2007). Phenomenology has a strong philosophical assumption which rest on some common grounds: the study of the lived experiences of persons, the view that these experiences are conscious ones and the development of descriptions of the essence of these experiences (Van Manen, 1990; Moustakas, 1994) cited in Creswell (2007). Phenomenology is quite consistent with the contact theory which asserts that with experience, two people who may be in 'conflict' are likely to resolve it.

This study was to provide evidence on what pupils with visual impairments (the blind) say about their friendship formation with peers without visual impairment, using ideas and views of their peer relationships, interactions, and peer acceptance. It was, therefore, important to determine pupils' experiences of friendship formation through phenomenology. Daley and Weisner (2003) found out that most pupils have an explanatory model that can be quite rich and complex. The authors noted that pupils "have a kind of blended, layered sense of self and identity drawing from and using typical identities and experiences, yet framed within a life of disability" (p. 38). It was, therefore, expedient to use phenomenology in order to allow pupils to provide complex and rich experiences to describe their friendship formation in ways that may be selectively different from those described in the literature on typically developing friendships, but nonetheless sufficient for analysis and comparison in their own right.

\subsection{Research Setting}

This study was conducted in three basic schools practicing the inclusive education project in Ghana. The schools were Ghana National Basic School at Cape Coast, Central Region, Avakpedome Basic School in the Volta Region and St. Joseph College of Education Basic School in the Brong Ahafo Region. These schools, Ghana National Basic School and St. Joseph College of Education Basic School, were chosen for the study because they were the only basic schools that were situated near Special Schools (Cape School for Deaf and Bechem School for the Deaf respectively) where the pupils with visual impairments could use their hostels. They have also been mandated by the Ministry of Education of Ghana to admit the pupils with visual impairment from the units for the visually impaired. Although Avakpedome Basic School is not situated near any special school; it has been mandated by the Ghana Education Service to admit and enrol pupils with visual impairments in their settings (Ministry of Education, 2005:7). These three basic schools have been identified in those regions over the past ten years to conduct a pilot project which will determine the success of the conversion of basic schools into full-service centres (inclusive schools) for pupils with visual impairments. This research was extended to those three primary schools to provide answers to the question of social participation of pupils with visual impairment in school activities.

\subsection{Sample}

The sample for the study was 14 people. Fourteen (14) pupils comprising of 4 pupils respectively from Ghana National Basic School, Cape Coast and Avakpedome Basic 
School, Adidome and 6 pupils from St. Joseph College of Education Basic School, Bechem also formed part of the sample size. Purposive sampling technique was used in selecting the sample for the study. I did so according to pre-selected criteria relevant to the particular research problem thus selecting only pupils with visual impairment to examine their formations in the affected schools. The power and logic of purposeful sampling is that a few cases studied in depth yield many insights about the topic. Purposive sampling was used to increase the utility of data obtained from the small samples. By purposive sampling technique, I handpicked the pupils with visual impairment because they were in a good position to tell their experiences as far as their relationship with others in school social activities were concern. All pupils with visual impairment in the schools were therefore, handpicked to take part in the study.

Table 1: The Breakdown of the Sample Size Involved in the Study

\begin{tabular}{|l|c|}
\hline School & Pupils with visual impairment \\
\hline Ghana National Basic School, Cape Coast, & 4 \\
\hline Avakpedome Basic School, Adidome & 4 \\
\hline St. Joseph College of Education Basic School, Bechem & 6 \\
\hline Total & $\mathbf{1 4}$ \\
\hline
\end{tabular}

\subsection{Data Collection Instruments}

One-on-one interactions was adopted to elicit data from pupils for the study. A semistructured interview guide was used. The questions were phrased to allow unique responses from each interviewee as suggested by Macmillan and Schumacher (2001). The items were designed and reflected on the key issue raised in the research problem.

\subsection{Data Collection Procedures}

Content validity was adopted to validate the interview items. With this, the items were designed and covered the key theme raised in the research question. Natural settings, such as, the participating schools were used as places in which the one-on-one interviews were conducted. I recorded precisely, almost literal, and detailed descriptions of the pupils. This was done by using two note takers and a recorder to record the interviews with the participating pupils. To ensure reliability of the instruments, the items were modified through reviews. These were comments and suggestions made by four experts in the field of qualitative researcher some of which were Professors and Senior Lecturers in academia (University of Education, Winneba, Ghana). Their knowledge in the area of research and practice was timely as far as the study was concerned. The corrections made were effected in the items. The interview was conducted using an interview guide within the school premises. The main procedure for conducting the interviews was through the use of recorders and note takers, and each interview lasted between 40 to 45 minutes.

\subsection{Ethical Consideration}

'Informed consent' was obtained from the authorities of the school prior to the commencement of the study. This was done via a letter from me seeking permission to 
conduct the study in their schools. The students who took part in this study were personally informed of the purpose and the procedures involved in gathering the data for the study by the researcher before the study was conducted. The participants were, after the sampling, asked to voluntarily opt to accept to take part in the study, they were therefore not forced to respond to the instruments in this study. The participants were assured of confidentiality of any information they would give, and that no third party would have access to the personal information given out. The researcher also explained to the participants that they could choose to opt out of the research when they wish to discontinue the process. The researcher explained to the participants that their names will not be needed in the course of the data collection but rather their responses will be coded to ensure confidentiality. Again, the researcher sought the permission of participants to use the tape recorder during the interview session in order to capture detailed data while concentrating on listening and prompting participants. Above all, I assured participants that information given out was mainly for academic purpose and for national policy directives.

\subsection{Data Analysis}

Thematic analysis was used for the analysis of the data. The analysis process involves familiarising oneself with the data, generating codes, searching for themes, defining and naming themes and producing a thematic description (Fossey et al. 2002; Braun \& Clarke 2006). First, all the audio-recorded interviews were transcribed in a Word document. The author listened to the interviews back-to-back and reviewed the transcript and field notes, for an overall comprehensive understanding. The second stage involved developing initial limited codes. The coding process involved a formal system of identifying ideas from the transcript. The author then used a focused coding process to identify additional codes, and then linked them to the remaining transcribed data. The coding process continued until saturation was reached, that is, no new concepts emerged from successive rounds of reviewing and coding (Braun \& Clarke, 2006; Saunders et al., 2018). The identified codes were further grouped into meaning unit, code and theme (see Table 3). The initial and focused coding and categorisation themes were done in consultation with experts who have years of experience in inclusive education and qualitative research. I employed several techniques to ensure methodological rigour, thus, the validity and reliability of the results. The study adhered to the four principles for conducting qualitative research - credibility, confirmability, transferability and dependability (Creswell \& Miller, 2000).

The table illustrate the gender distribution of the respondents. Data from the Table shows that the male population (students) of the sample size that were interviewed were $9(64.3 \%)$ while the female pupils were 5 representing $35.7 \%$. This means that majority of the pupils were males and could have therefore shared their social experiences in the schools with confidence. The Table shows that majority of the students were within the age range of 16 and 20 years. They were therefore grown enough to narrate their social experiences in the schools. 

IMPAIRED PUPILS IN SELECTED INCLUSIVE BASIC SCHOOLS IN GHANA

Table 2: Demographic Characteristics of Participants

\begin{tabular}{|c|c|c|c|c|}
\hline Age Range & & & Male & Female \\
\hline $10-15$ & & & 3 & 2 \\
\hline $16-20$ & & & 6 & 3 \\
\hline Total & & & 9 & 5 \\
\hline Class & Male & Female & Total & $\%$ \\
\hline JHS 1 & 2 & 1 & 3 & 21.4 \\
\hline JHS 2 & 3 & 2 & 5 & 35.7 \\
\hline JHS 3 & 4 & 2 & 6 & 42.9 \\
\hline Total & 9 & 5 & 14 & 100 \\
\hline \multicolumn{3}{|l|}{ School } & Male & Female \\
\hline \multicolumn{3}{|l|}{ Ghana National Basic School } & 2 & 2 \\
\hline \multicolumn{3}{|l|}{ Avakpedome Basic School } & 3 & 1 \\
\hline \multicolumn{3}{|c|}{ St. Joseph College of Education Basic School, Bechem } & 4 & 2 \\
\hline \multicolumn{3}{|l|}{ Total } & 9 & 5 \\
\hline
\end{tabular}

\section{Results}

\subsection{Analysis of Data from the Interview}

This section analyses data that emerged from the interactions with the pupils. The data has been analysed under themes that emerged from the data collected.

\subsubsection{Friendship Formation between Pupils with Visual Impairments and their Peers without Visual Impairments in the Inclusive Schools in Ghana}

To answer this theme, the data collected from the pupils who were visually impaired were used. Pupils' responses were grouped according to how friendships were formed or otherwise between pupils and thus presented under the following themes.

\section{A. Helping and Playing Together with the Visually Impaired (Being Assisted or Supported)}

Per the Friendship formations Networks in the Schools, the interaction with the pupils revealed that the non-visually impaired population were friendly to them and gave them assistance when and as demanded. A remark made by a pupil in School 'A' attested to this:

"Am friendly to the non-visually impaired and some are also friendly to me. We greet each other and sometimes, they help me. Sometime, some of them will talk to me and ask me questions as how I manage things. Some are ready to move and do things with us but some of them too think that it will be difficult to interact with us." (Verbatim response from a pupil in School A)

Another pupil said that: 
"Friendship is good. Sometimes we play together, they help us. They support when we want to locate certain places in the classroom and school. Sometimes you may get assistance and may not get but others too would ask to help you when they see you coming." (Verbatim response from a pupil in School B)

It was evident from the analysis of the comments from the pupils that, the nature of friendship network among the pupils in the schools centered on being assisted or helped by the non-visually impaired.

A pupil in School B commented that the nature of friendship network with the non-visually impaired was cordial though it lacked intimacy:

"The friendship is very cordial even as from primary level and anywhere I go. At times, there are some people who may not be ready for me in terms of intimacy thus sharing our secrets but when they begin to talk too much when chatting I discard such friendship. I will say it's very cordial." (Verbatim response from a pupil in School B)

One other pupil remarked this way:

"Initially, some people think visual impairment is contagious and would not like to come nearer to you. But as time went on, they came closer and got to know how we got impaired and this made people draw closer to me and assist me in all things. Some will like to come closer but others do not want to come closer." (Verbatim response from a pupil in School C).

It seemed clear that there existed some levels of friendship with the non-visually impaired in the schools as depicted by the comments from the pupils with visual impairment. These revelations are consistent with the "contact theory", which noted that as mainstream pupils in schools implementing inclusion programmes get closer to their marginalized peers, their attitudes become more positive and they develop positive relationship with each other.

\section{B. Segregated Interactions/relations in Play Activities}

One pupil in School C, indicated that the friendship system in the school did not favour her because, she only had her fellow visually impaired mate as a friend though, the nonvisually impaired did not hate her as such. They treated them with bias and would not spend time with them. His comments went this way:

"The non-visually impaired? some do not play, or interact or even want to assist or get closer to me. They play with their fellow non-visually impaired friends just as I do with the visually impaired. Sometimes they shout on me and I don't like that. I want to play with them but they are not ready to accept me." (Verbatim response from a pupil in School C) 
Another pupil remarked this way:

"They are not good, some of them. They only relate well with the non-visually impaired more than us. They treat their fellow non-visually impaired well but shout on us." (Verbatim response from a pupil in School B)

The comments from the pupils on parallel friendship revealed that there were mixed reactions on this issue. While others had and made friends with the non-visually impaired, others did not experience that. Having been in the school through primary stage to the Junior High, one would expect that the nature of friendship network would favour all pupils in the schools but that did not exist. That is not to say that there is total absence of friendship network with the non-visually impaired population since some of the pupils reported having positive experiences with the non-visually impaired.

\section{Isolated, Non-related Interactions}

On mutual friendship formation, the data revealed events and elements that would make significant impressions on the intimacy or quality of their friendship formation with the non-visually impaired peers in the schools. On this, a pupil commented this way:

"I experience very uncordial relationship; we don't chat with each other well. I don't also talk to each other about things we like or dislike in school." (Verbatim response from a pupil in School A)

\section{One-way Intimate Discussions of Personal Matters}

The analysis of the pupils' comments indicated that the non-visually impaired did not disclose their intimate feelings to the visually impaired as they (visually impaired) did Another pupil also stated:

"With others they shy away. I am very intimate; I visit them at various places. I discuss a lot on visual impairment. I try to explain to my non-visually impaired peers how we behave, and what we are capable of doing. When sometimes something is bothering me, I discuss with my friends. The only thing is that they don't disclose their secrecy to us but want us to do. That one we will not do." (Verbatim response from a pupil in School A)

One pupil however, acknowledged that:

Some tell me very intimate matters and advice and encourage me. Sometimes I sound funny and we make funs together. I feel like a family member. (Verbatim response from a pupil in School A) 


\section{E. Sharing Things in Common, Jokes, Play}

Contrary to the majority views expressed in School 'A', Pupils in School B expressed views that communicated positive and mutual relationship between them and the nonvisually impaired peers. For example, a pupil noted that:

"Some take me as their brother and treat me well and assist me and this has made me happy. The interactions with the non-visually impaired peers is partly good. Some always come to greet me and find out what they can do for me. People want to know how we become impaired. We disclose to them and they become very close with us. We share things in common, jokes, play and discuss our problems." (Verbatim expression from a pupil in School B)

Similarly, a pupil also described with passion, the kind of relationship that she experienced with the non-visually impaired peers in their school:

"By nature of friendship, some of the non-visually impaired peers are very mutual, how they come near me so as to know what brought about my impairment especially, they tend to do anything for me. Sometimes they do admire everything I do and these friends will always like to move and play with me." (Verbatim expression from a pupil in School C)

The analysis of the viewpoints of the pupils revealed three things: mutual relations, partial mutual friendship and total absence of mutual relationship in the schools. While some of the pupils noted that they were mutually engaged in positive relationship formations with the non-visually impaired, some thought otherwise and yet others described it as only partial. Partial in the sense that it was one sided.

Table 3: A Thematic Table Showing the Themes Realized from the Qualitative Analysis

\begin{tabular}{|l|l|l|}
\hline Meaning Unit & \multicolumn{1}{|c|}{ Code } & \multicolumn{1}{c|}{ Theme } \\
\hline $\begin{array}{l}\text { "Am friendly to the non-visually impaired and some are } \\
\text { they help me. Sometime, some of them will talk to me and } \\
\text { ask me questions as how I manage things. Some are ready } \\
\text { to move and do things with us but some of them too think } \\
\text { that it will be difficult to interact with us." }\end{array}$ & $\begin{array}{l}\text { Helping and playing } \\
\text { together, with the } \\
\text { visually impaired }\end{array}$ & $\begin{array}{l}\text { Nature of the } \\
\text { friendship formation } \\
\text { process }\end{array}$ \\
\hline \multicolumn{2}{|l|}{$\begin{array}{l}\text { "Friendship is good. Sometimes we play together, they } \\
\text { help us. They support when we want to locate certain } \\
\text { places in the classroom and school. Sometimes you may } \\
\text { get assistance and may not get but others too would ask } \\
\text { to help you when they see you coming. The friendship is } \\
\text { very cordial even as from primary level and anywhere I } \\
\text { go. At times, there are some people who may not be ready } \\
\text { for me in terms of intimacy thus sharing our secrets but } \\
\text { when they begin to talk too much when chatting I discard }\end{array}$} & Being assisted or \\
\hline
\end{tabular}




\begin{tabular}{|l|l|l|}
\hline \hline $\begin{array}{l}\text { such friends. I will say it's very cordial. Initially, some } \\
\text { people think visual impairment is contagious and would } \\
\text { not like to come nearer to you. But as time went on they } \\
\text { came closer and got to know how we got impaired and } \\
\text { this made people draw closer to me and assist me in all } \\
\text { things. Some will like to come closer but others do not } \\
\text { want to come closer." }\end{array}$ & & \\
\hline \multicolumn{2}{|l|}{} & \\
\hline $\begin{array}{l}\text { "The non-visually impaired? some do not play, or } \\
\text { interact or even want to assist or get closer to me. They } \\
\text { play with their fellow non-visually impaired friends just } \\
\text { as I do with the visually impaired. Sometimes they shout } \\
\text { on me and I don't like that. I want to play with them but } \\
\text { they are not ready to accept me." }\end{array}$ & $\begin{array}{l}\text { Segregated interactions, } \\
\text { actions and in play }\end{array}$ & Parallel pattern of \\
\hline
\end{tabular}

"They are not good, some of them. They only relate well with the non-visually impaired more than us. They treat their fellow non-visually impaired well but shout on us."

\begin{tabular}{|l|l|l|}
\hline $\begin{array}{l}\text { "I experience very uncordial relationship; we don't chat } \\
\text { with each other well. I don't also talk to each other about } \\
\text { things we like or dislike in school." }\end{array}$ & $\begin{array}{l}\text { Isolated, non-related } \\
\text { interactions on personal } \\
\text { issues. Total absence of } \\
\text { interpersonal } \\
\text { interactions }\end{array}$ & $\begin{array}{l}\text { Non-intimate } \\
\text { unfriendship } \\
\text { formations }\end{array}$ \\
\hline \multicolumn{3}{|c|}{} \\
$\begin{array}{l}\text { "With others they shy away. I am very intimate; I visit } \\
\text { them at various places. I discuss a lot on persons with } \\
\text { disability. I try to explain to my non-visually impaired } \\
\text { peers how we behave, and what we are capable of doing. } \\
\text { When sometimes something is bothering me, I discuss } \\
\text { with my friends. The only thing is that they don't } \\
\text { disclose their secrecy to us but want us to do. That one } \\
\text { we will not do." }\end{array}$ & $\begin{array}{l}\text { One-way intimate } \\
\text { discussions of personal }\end{array}$ & $\begin{array}{l}\text { friendship } \\
\text { formations }\end{array}$ \\
\hline
\end{tabular}

\begin{tabular}{|c|c|c|}
\hline $\begin{array}{l}\text { "Some tell me very intimate matters and advice and } \\
\text { encourage me. Sometimes I sound funny and we make } \\
\text { funs together. I feel like a family member" }\end{array}$ & & \\
\hline $\begin{array}{l}\text { Some take me as their brother and treat me well and } \\
\text { assist me and this has made me happy. The interactions } \\
\text { with the non-visually impaired peers is partly good. } \\
\text { Some always come to greet me and find out what they } \\
\text { can do for me. People want to know how we become } \\
\text { impaired. We disclose to them and they become very close } \\
\text { with us. We share things in common, jokes, play and } \\
\text { discuss our problems By nature of friendship, some of the } \\
\text { non-visually impaired peers are very mutual, how they } \\
\text { come near me so as to know what brought about my } \\
\text { impairment especially, they tend to do anything for me. } \\
\text { Sometimes they do admire everything I do and these } \\
\text { friends will always like to move and play with me." }\end{array}$ & $\begin{array}{l}\text { Treating them well, } \\
\text { sharing things in } \\
\text { common, jokes, play. } \\
\text { They would do } \\
\text { anything for the } \\
\text { visually impaired. }\end{array}$ & $\begin{array}{l}\text { Mutual friendship } \\
\text { formations (mutually } \\
\text { engaged in positive } \\
\text { relationship } \\
\text { formations) }\end{array}$ \\
\hline
\end{tabular}




\section{Discussions}

\subsection{The Nature of Friendship Formation that Exists Between Pupils with Visual Impairment and their Peers without Visual Impairment in the Inclusive Schools in Ghana}

\section{A. Helping and Playing Together}

The formation of friendships in the schools, took the form of 'I'll help, assistance" on needed bases. The findings were that the pupils played together with the sighted as well as got assistance from them. The non-visually impaired helped the visually impaired whenever they needed it, and that the visually impaired and non-visually impaired helped each other so they could get things done quickly. It should be noted however, that some of the pupils viewed their friendship formation experiences in the schools as negative. For instance, the findings revealed that the non-visually impaired did not make friends with some of the visually impaired and were not ready to accept them in social activities. The study thus revealed that students without visual impairment cooperated and related among themselves more than they did with those who were visually impaired.

\section{B. Being Assisted or Supported}

The analysis of my qualitative data revealed elements that described the nature of friendships that existed in the schools. It was evident from the analysis of the comments of the pupils that, the friendship network in the schools centered on being assisted or helped by the non-visually impaired. The pupils' insightful descriptions showed the nature of friendship that existed in the schools. The pupils noted that they played together with the non-visually impaired as well as got assistance from them. Evans and Meyer (2001: 167-176) considered this nature of friendships to be specific to the relationships between children with disabilities and peers without disabilities, and involved some type of imbalance or inequity in interactions between the members of the dyad. These relationships were typically characterized by one member of the dyad viewing the other as different (Inclusion Child) and in need of special consideration or help. Similarly, in two studies, Avramadis (2012) examined the friendships of primary school children with and without disabilities in England. Although, it was found out that these students were less popular than students without disabilities, they were equally likely to be members of the friendship clusters of the class and occupied similar levels of network centrality as their non-disabled peers. Arndt, Lieberman, \& James, 2014) noted that pupils with visual impairment created friendships with sighted alongside with non-sighted peers in different contexts and in schools. In schools however, they tended to create relationships with individuals that were less accepted by typically developing peers (Rosenblum, 2000) and approximately $10 \%$ of their social networks consisted of individuals with visual impairments as well (Kef, Hox, \& Habekothe, 2000). 
Pupils with visual impairment tend to have smaller friend networks and be lonelier than their sighted peers (Kef, 2002). This has a great negative impact on adolescents' well-being and it is not only the quantity of friendships that affect individuals' well-being but also the quality (Rosenbaum \& Gorter, 2012). It is not common for research to examine friendship quality, due to multiple ethical considerations, but friendships and peer support is crucial for the quality of long-term social networks of pupils with visual impairment (Kef, 2002). Once relation has been established, the friendship tends to move deeper into a reciprocal and mutual relationship. These kinds of friendship have the potential for promoting meaningful inclusiveness as embedded in the contact theory which stated that negative perceptions towards others with disabilities change when both parties work together and become familiar with each other's potentials and challenges.

My findings also showed that some non-visually impaired pupils seemed to have had care-giving relationships with peers who had disabilities rather than friendships. These relationships (I'll Help, and Inclusion Child) were typically characterized by one member of the dyads viewing the other as different (Inclusion Child) and in need of special consideration or help (I'll Help). For instance, the pupils noted that, some of the non-visually impaired initially thought that visual impairment was contagious and would not like to come nearer to them and thus help them but as time went by, they came closer and got to know how they became impaired and thus assisted them in doing things. This means that pupils with visual impairment were considered as an inclusion child' especially at the initial stages of inclusion into the mainstream. Anderson, et al. (2011) interviewed students without disabilities to find out about their experience of friendship with students with disabilities. The children described mutually beneficial friendships, through language such as "he cares about me and I care about him" (p. 82). Having a disability can be challenging and according to statements of adolescents with vision impairments in Finland (Huurre \& Aro, 2000) having a supportive social network with friends was helpful in order to cope with the impairment. As reported by the adolescents themselves, the contribution and the role of their friends was perceived as even more important than the one of the close family members, classmates and other colleagues (Kef, Hox, \& Habekothe, 2000). The proposition of the contact theory by Allport is that knowledge of pupils with disabilities by the non-disabled is likely to change their negative attitudes towards them and thus promote acceptance. These revelations were consistent with the "contact theory", which notes that as regular classroom pupils experiencing inclusion programmes get closer to their marginalized peers, their attitudes become more positive and they develop positive relationships with them (Yuker, 1988).

\section{Segregated Interactions (Isolated, Non-related Interactions)}

It should be noted however, that some of the pupils viewed their friendship experiences in the schools as negative or what would be termed as parallel. For instance, the pupils noted that the non-visually impaired did not make friends with them and were not ready 
to accept them instead made friends with their typical peers. The pupils also buttressed that the non-visually impaired did not make friends with them but treated their fellow non-visually impaired peers cordially while shouted at them. This means that students without disability cooperated and related among themselves more than they did with those who with visual impairment. These could be negative experiences in an environment that they are expected to build positive relationship with peers and thus acquire social skills capable of integrating into the mainstream of the larger society. (Khadka, Margrain, Woodhouse, \& Davies, 2012) reported that when feeling socially excluded, not accepted by peers at school and when they had not formed quality friendships, pupils with visual impairments, usually with low vision, tried to hide their disability by not using low vision devices, abandoned braille and refused to use specially adapted materials created to help them academically and consequently they became stressed (de Verdier, 2016). A large-scale study from Norway found out that students with disabilities and those with behaviour problems had a considerably more difficult time finding and keeping friends (Frostad \& Pijl, 2007). These researchers found out that students with special needs were less popular, had fewer friends, and participated less often as members of a sub-group. These experiences could be encapsulated into a friendship networked described by Evans and Meyer (2001) as "guest friend" where the non-visually impaired perceives the visually impaired as guest and would not play with them. These findings tend to contradict the contact theory which expects both categories of pupils to build on experiences that would change misconceptions and wrong perceptions in order to strengthen stronger relationships in regular schools where the child with visual impairments were being included. As noted in literature, Anderson (2006) opined that, it often may be the case that pupils with disabling conditions, particularly those who are more visible and significant, though included in the classroom, may remain outsiders. The foregoing discussions revealed experiences that were extremely varied and included both stories of positive relationships and experiences of social isolation or loneliness in the schools. Pupils with visual impairment had smaller social networks and less friends than sighted adolescents (Pinquart \& Pfeiffer, 2011) even compared to non-visually impaired peers with chronic conditions (Huurre \& Aro, 2000). Therefore, they spent less leisure time in activities with friends compared to non-visually peers (Huurre \& Aro, 2000; Lifshitz, Hen, \& Weisse, 2007) and had even less interactions with them through phones (Kroksmark \& Nordell, 2001).

\section{One-way Intimate Discussions}

My qualitative data revealed events and elements that made significant impressions on the intimacy or quality of their friendship with the non-visually impaired peers in the schools. Three indicators of intimate relationships were revealed: mutual relations, partial mutual friendship and total absence of mutual relationship in the schools. While some of the pupils noted that they were mutually engaged in positive relationship with the non-visually impaired, some thought otherwise and yet others described it as only partial. It was evident from the analyses of my data that some of the non-visually 
impaired peers took the visually impaired as brothers and treated, as well as assisted them in activities that made them happy. The pupils also asserted that they shared things in common, jokes, play and discussed their problems together. Brotherly or affectionate treatment, sharing and discussing problems together with sighed were very key in explaining the mutual relationships that existed in the schools. These were the key defining events that could corroborate in facilitating socialization in the schools. These experiences support the contact theory since it has the potentials to promote acceptance of the visually impaired in regular school settings. Wager and Bailey (2005:76-86) described mutual relationship as someone you have a significant relation with and someone you want to spend time and share experiences with. Understandably, talking together, playing jokes together and mutually treating the visually impaired differently defined the respondents' assertion of mutual friendship in the schools. In a study with pupils with disabilities and their close friends about how they negotiated their friendship and their feelings about belonging, Salmon (2012) noted that all of these young people were engaged in rich and fulfilling relationships. In addition to the qualitative data, quantitative data was also utilised to triangulate the findings.

\section{E. Sharing Things in Common, Jokes and Play}

Positive interactions, sharing jokes and special treatment of the visually impaired could best explain the mutual relationships that existed in the schools. Howes (1983) discovered in a study that mutual preference was the easiest criteria for preschool friendship dyads to meet, whereas mutual enjoyment expressed by positive affect, the most critical aspect of friendship, was the hardest to achieve. As noted elsewhere in the data analyses, talking together, playing jokes together and mutually treating the visually impaired differently defined the mutual friendship in the schools. These elements can strengthen the experiences of pupils with visual impairments and their non-disabled peers and thus facilitating the acceptance of the visually impaired in inclusive settings as propounded by the contact theory.

As noted early on in the data analyses, the pupils also described elements of partial mutual relationships in the schools. A pupil noted that the nature of friendship with the non-visually impaired peers was partly mutual in the sense that some of the students or friends did like to disclose their secrets with her, but some did not but expected her to do. The pupils noted the non-visually impaired did not disclose their secrecy to them but wanted them (visually impaired) to do. As noted earlier in the literature, pupils with visual impairment open up to in terms of been intimate to the non-visually impaired without it being reciprocated by the non-visually impaired. Van der Klift and Kunc (1994) however warned that one-sided help is not and can never be the basis of friendship because it would lose the reciprocity that is essential in maintaining a balanced friendship. Buttressing that, Dunn (2004) stated that mutual affection is crucial as it distinguishes friendship from one child's desire to be liked by a peer, when that other child does not return the preference. Pupils with visual impairment opens up to in terms of been intimate to the non-visually impaired without it being reciprocated by the non- 
visually impaired. Reciprocity and or mutuality hinges on contact in an inclusive environment and if mutual relations does not exist then it puts the social participation of the visually impaired at stake and contravenes the philosophy of the contact theory which notes that creating an environment within which pupils with visual impairment can interact meaningfully without name calling by others is pivotal to negating the poor selfconcept and potential for social isolation which is often associated with being visually impaired (Aristotle, 2004).

The analysis of my qualitative data revealed some level of absence of mutual relationship in the schools. For instance, the pupils asserted they did not talk to the nonvisually impaired other about things they liked or disliked in school. These can be negative experiences but what should be examined is the level of social competence of the pupils which could be looked in a different study. Studies have shown that adolescents with visual impairments can find high school socially challenging (Rosenblum, 2000). Allport (1954) warned in his contact theory that superficial contact between members of different groups can, in fact, have negative consequences on the socialization of pupils with visual impairments who are being educated in mainstreamed schools.

It is evident from the discussions that, there existed some levels of friendship with the non-visually impaired in the schools and this friendship network centered on being assisted or helped by the non-visually impaired. The analysis of my qualitative data revealed three things: mutual relations, partial mutual friendship and total absence of mutual relationship in the schools. While some of the pupils noted that they were mutually engaged in positive relationship with the non-visually impaired, some thought otherwise and yet others described it as only partial.

\section{Strengths and Limitations}

Given the title of the research and the fact that it was conducted in inclusive basic schools, a major limitation is the non-inclusion of pupils who were not visually impaired.

\section{Recommendation}

Based on the findings, I recommended that educational authorities in Ghana should put in place, a time for play and socialization that will solely focus on the formation of friendship between pupils who are visually impaired and the non-visually impaired and that pupils who are visually impaired should be assisted by teachers to develop the capacity to make and maintain stable and satisfying friendships with the non-visually impaired peers. 


\section{Conclusion}

From the findings of the study, it can be concluded that there is an unhealthy friendship patterns in the schools.

\section{Disclosure Statement}

The author declare that he had no financial or personal relationships that may have inappropriately influenced him in writing this article.

\section{Funding Information}

The author received no financial support for the research, authorship, and/or publication of this article.

\section{About the Author}

Adam Awini is a lecturer with the Department of Special Education, University of Education, Winneba in Ghana. The author holds a PhD in special education from the university he currently lectures. He has taught at the university for a number of years and published in many peer-reviewed journals across the world. He is passionate in the education of learners with disabilities, more especially, in inclusive learning environments. He has equally supervised a considerable number of research work in the university, both undergraduate and graduate levels.

\section{References}

Aboud, F., \& Mendelson, M., 1996, 'Determinants of friendship selection and quality: Developmental perspectives', In W. Bukowski, A. Newcomb, \& W. Hartup (Eds.). The company they keep: Friendships in childhood and adolescence. Cambridge studies in social and emotional development (pp. 87-113), Cambridge Univ. Press, Cambridge, UK.

Allport, G.W., 1954, The nature of prejudice, Addison-Wesley, Oxford.

Anderson, K., Balandin, S., \& Clendon, S., 2011, 'He cares about me and I care about him: Children's experiences of friendship with peers who use $\mathrm{AAC}^{\prime}$, Augmentative and Alternative Communication, 27(2), 77-90.

Aristotle, 2004, Nicomachen ethics, Penguin, London.

Arndt, K., Lieberman, L., \& James, A., 2014, 'Supporting the Social Lives of Adolescents Who

Are Blind: Research to Practice', Clearing House: A Journal of Educational Strategies, Issues and Ideas, 87, 2, 69-74.

Asher, S., Parker, J., \& Walker, D., 1996, ‘Distinguishing friendship from acceptance: Implications for intervention and assessment', In W. Bukowski, A. Newcomb, \& W. Hartup (Eds.). The company they keep: Friendships in childhood and adolescence. 
Cambridge studies in social and emotional development (pp. 336- 405). Cambridge Univ. Press, Cambridge, UK.

Avoke, M.K. \& Avoke, S.K., 2004, Inclusion, rehabilitation and transition services in special education, Department of Special Education, UEW, Winneba.

Berndt, T.J., 1996, 'Exploring the effects of friendship quality on social development', In W. Bukowski, A. Newcomb, \& W. Hartup (Eds.). The company they keep: Friendships in childhood and adolescence. Cambridge studies in social and emotional development (pp. 346-365), Cambridge Univ. Press, Cambridge, UK.

Braun, V., \& Clarke, V. 2006, “Using Thematic Analysis in Psychology." Qualitative Research in Psychology 3 (2): 77-101.

Bukowski, W.M., Hoza, B., \& Boivin, M., 1994, 'Measuring friendship quality during pre and early adolescence: The development and psychometric properties of the friendship qualities scale', Journal of Social and Personal Relationships, 11, 471-484.

Chadha, R., \& Subramanian, A., 2011, 'The effect of visual impairment on quality of life of children aged 3-16 years', British Journal of Ophthalmology, 95, 5, 642-645.

Chak, M., \& Rahi, J., 2007, 'The health-related quality of life of children with congenital cataract: Findings of the British Congenital Cataract Study', British Journal of Ophthalmology, 91, 7, 922-926.

Chamberlain, B., Kasari, C., \& Rotherham-Fuller, E., 2007. 'Involvement or isolation? The social networks of children with autism in regular classrooms', Journal of Autism and Developmental Disorders, 37, 230-242. doi: 10.1007/s10803-006-0164-4

Creswell, J.W., 2013, Steps in conducting a scholarly mixed methods study. DBER Speaker Series, Paper 48, Department of Educational Psychology University of NebraskaLincoln. http://digitalcommons.unl.edu/dberspeakers/48. Retrieved on 26/5/2015, Lincoln.

Creswell, J.W., \& Miller, D.L. 2000, “Determining Validity in Qualitative Inquiry.” Theory Into Practice 39 (3): 124-130.

De Verdier, K. (2016). Inclusion in and out of the classroom: A longitudinal study of students with visual impairments in inclusive education. British Journal of Visual Impairment, 34(2), 130-140.

De Vet, E., Waitt, G., \& Gorman-Murray, A., 2012, 'How dare you say that about my friend': Negotiating disability and identity within Australian high schools', Australian Geographer, 43(4), 377-391.

Dunn, J., 2004, Children's friendships: The beginnings of intimacy, Blackwell, Oxford.

Elsman, E.B.M., van Rens, G.H.M.B., \& van Nispen, R.M.A., 2019, 'Quality of life and participation of young adults with a visual impairment aged 18-25 years: comparison with population norms', Acta ophthalmological, 97, 2, 165-172.

Estell, D.B., Jones, M.H., Pearl, R., \& van Acker, R., 2009, 'Best friendships of students with and without learning disabilities across late elementary school', Council for Exceptional Children, 76(1): 110-124. 
Evans, I.M., \& Meyer, L.H., 2001, 'Having friends and Rett syndrome: How social relationships create meaningful contexts for limited skills', Disability and Rehabilitation, 23, 167-176. doi:10.1080/09638280150504243

Foley, K.R., Blackmore, A.M., Girdler, S., O'Donnell, M., Glauert, R., Llewellyn, G., \& Leonard, H., 2012, 'To feel belonged: The voices of children and youth with disabilities on the meaning of wellbeing', Child Indicators Research, 5, 375-391.

Fossey, E.,C. Harvey, F. McDermott, \& Davidson, L. 2002, “Understanding and Evaluating Qualitative Research. Australian and New Zealand Journal of Psychiatry 36 (6): 717-732. doi:10.1046/j.1440-1614.2002.01100.x.

Frostad, P., \& Pijl, S.J., 2007, 'Does being friendly help in making friends? The relation between the social position and social skills of students with special needs in mainstream education', European Journal of Special Needs Education, 22, 15-30.

Howes, C., 1983, 'Patterns of friendship', Child Development, 54, 1041-1053. doi: $10.2307 / 1129908$

Huurre, T., \& Aro, H., 2000, 'The Psychosocial Well-Being of Finnish Adolescents with Visual Impairments versus Those with Chronic Conditions and Those with No Disabilities', Journal of Visual Impairment \& Blindness, 94, 10, 625-637.

Lehohla, M. \& Hlalele, D., 2012, 'Inclusive Classrooms: An Ecosystemic Perspective', Journal of Human Ecology, 37(3): 189-201.

Khadka, J., Ryan, B., Margrain, T.H., Woodhouse, J.M., \& Davies, N., 2012, 'Listening to voices of children with a visual impairment: A focus group study', British Journal of Visual Impairment, 30, 3, 182-196.

Kef, S. 2002, 'Psychosocial Adjustment and the Meaning of Social Support for Visually Impaired Adolescents', Journal of Visual Impairment \& Blindness, 96(1), 22-37.

Kef, S., Hox, J.J., \& Habekothe, H.T., 2000, 'Social networks of visually impaired and blind adolescents: Structure and effect on well-being', Social Networks, 22, 73-91

King, G., Chaters, T., Miller P.J., MacKinnon, E., \& Havens, L., 2000, 'Success in life of older adolescents with cerebral palsy', Quantitative Health Research, 10, 734-739.

King, G., Law, M., King, S., Rosenbaum, P., Kertoy, M.K., \& Young, N.L., 2003, 'A conceptual model of the factors affecting the recreation and leisure participation of children with disabilities', Physical \& Occupational Therapy in Paediatrics, 23(1), 63-90.

Kroksmark, U., \& Nordell, K., 2001, 'Adolescence: The Age of Opportunities and Obstacles for Students with Low Vision in Sweden', Journal of Visual Impairment $\mathcal{E}$ Blindness, 95, 4, 213-225.

Lifshitz, H., Hen, I., \& Weisse, I., 2007, 'Self-concept, Adjustment to Blindness, and Quality of Friendship among Adolescents with Visual Impairments', Journal of Visual Impairment \& Blindness, 101(2), 96-107.

Macmillan, J.H. \& Schumacher, S., 2001, Research in education, Harper Publishers, New York. 
McCollum, A.B., 1998, 'Tradition, Folklore, and Disability: A Heritage of Inclusion', In Eiesland, N.L. \& Saliers, D.E. (Ed.), Human disability and the service of God: Reassessing religious practice, Abingdon Press, Nashville, (pp. 184).

McMaugh, A., 2011, 'Encountering disablement in school life in Australia: Children talk about peer relations and living with illness and disability', Disability $\mathcal{E}$ Society, 26(7), 853-866.

Meyer, L., \& Bevan-Brown, J., 2005, 'Collaboration for Social Inclusion', In D. Fraser, R. Moltzen, \& K. Ryba (eds.), Learners with Special Needs in Aotearoa (pp. 168-192), Thomson Dunmore Press, Victoria.

Ministry of Education, 2005, Education strategic plan: Policy targets and strategies. Volume 1. Author, Accra.

Nollett, C., Ryan, B., Bray, N., Bunce, C., Casten, R., Edwards, R., . . Margrain, T., 2019, 'Depressive symptoms in people with vision impairment: A cross-sectional study to identify who is most at risk', BMJ Open, 9, 1, E026163.

Parker, J.G., \& Asher, S.R., 1993, 'Friendship and friendship quality in middle childhood: Links with peer group acceptance and feelings of loneliness and social dissatisfaction,' Developmental Psychology, 29, 611- 621.

Pinquart, M., \& Pfeiffer, J.P., 2011, 'Associations of extroversion and parental overprotection with forming relationships with peers among adolescents with and without visual impairments', Journal of Visual Impairment $\mathcal{E}$ Blindness, 105,2, 96-107.

Prince, E. J., 2010, Exploring the effectiveness of inclusion: Is a sense of school belonging the key factor in understanding outcomes? Doctorate of Educational Psychology, University of Southampton.

Robinson, S. \& Truscott, J. (2013). Belonging and connection of school students with disability issues paper, Children with Disability Australia, Sydney.

Rosenblum, L.P., 2000, 'Perceptions of the impact of visual impairment on the lives of adolescents', Journal of Visual Impairment $\mathcal{E}$ Blindness, 94,7, 434-445.

Salmon, N., 2012, 'We just stick together': How disabled teens negotiate stigma to create lasting friendship', Journal of Intellectual Disability Research, Early View, 27, 195-202.

Sandstrom, M.J., Cillessen, A.H.N., \& Eisenhower, A., 2003, 'Children's appraisal of peer rejection experiences: Impact on social and emotional adjustment', Social Development, 12, 530-550.

Saunders, B., Sim, J., Kingstone, T., Baker, S., Waterfield, J., Bartlam, B., Burroughs, H., \& Jinks, C. 2018, "Saturation in Qualitative Research: Exploring its Conceptualization and Operationalization." Quality $\mathcal{E}$ Quantity 52 (4): 1893-1907. UNESCO., 2017. Guide for ensuring inclusion and equity in education. Paris: UNESCO

Van der Klift, E. \& Kunc, N., 1994, 'Beyond benevolence: Friendships and the politics of help', In J.S. Thousand, R.A. Villa, \& A.I. Nevin (Eds.), Creativity and collaborative learning: A practical guide for empowering students and teachers (pp. 391-402), Brookes, Baltimore.

Wager, J., \& Bailey, M., 2005, 'The I in inclusion', Individual indicators of inclusion across quality of life domains, 16(6), 76-86. 
Wong, D.K.P., 2006, 'Do contacts make a difference? The effects of mainstreaming on student attitudes toward people with disabilities', Research in Developmental Disabilities, 29, 70-82.

Yuker, H.E., 1988, 'The effects of contact on attitudes toward disabled persons: Some empirical generalisations,' In H. E. Yuker (Ed.) Attitudes toward persons with disabilities (262-274). Springer, New York.

Creative Commons licensing terms

Authors will retain the copyright of their published articles agreeing that a Creative Commons Attribution 4.0 International License (CC BY 4.0) terms wil be applied to their work. Under the terms of this license, no permission is required from the author(s) or publisher for members of the community to copy, distribute, transmit or adapt the article content, providing a proper, prominent and unambiguous attribution to the authors in a manner that makes clear that the materials are being reused under permission of a Creative Commons License. Views, opinions and conclusions expressed in this research article are views, opinions and conclusions of the author(s). Open Access Publishing Group and European Journal of Special Education Research shall not be responsible or answerable for any loss, damage or liability caused in relation to/arising out of conflict of interests, copyright violations and inappropriate or inaccurate use of any kind content related or integrated on the research work. All the published works are meeting the Open Access Publishing requirements and can be freely accessed, shared, modified, distributed and used in educational, commercial and non-commercial purposes under a Creative Commons Attribution 4.0 International License (CC BY 4.0). 